\title{
Risk Factors of Acute Pancreatitis in Oral Double Balloon Enteroscopy
}

\author{
Marcela Kopáčová ${ }^{1, *}$, Jan Bureš ${ }^{1}$, Stanislav Rejchrt ${ }^{1}$,Jaroslava Vávrová2, Jolana Bártovál, \\ Tomáš Soukup ${ }^{1}$, Jan Tomšr ${ }^{1}$ Ilja Tacheci ${ }^{1}$
}

\author{
${ }^{1}$ 2nd Department of Medicine - Gastroenterology, Charles University, Faculty of Medicine in Hradec Králové, University \\ Teaching Hospital, Hradec Králové, Czech Republic \\ ${ }^{2}$ Institute of Clinical Biochemistry and Diagnostics, Charles University, Faculty of Medicine in Hradec Králové, University \\ Teaching Hospital, Hradec Králové, Czech Republic \\ * Corresponding author: 2nd Department of Medicine - Gastroenterology, University Hospital, Sokolská 581, 50005 Hradec \\ Králové, Czech Republic; e-mail: marcela.kopacova@fnhk.cz
}

Summary: Double balloon enteroscopy (DBE) was introduced 15 years ago. The complications of diagnostic DBE are rare, acute pancreatitis is most redoubtable one (incidence about $0.3 \%$ ). Hyperamylasemia after DBE seems to be a rather common condition respectively. The most probable cause seems to be a mechanical straining of the pancreas. We tried to identify patients in a higher risk of acute pancreatitis after DBE. We investigated several laboratory markers before and after DBE (serum cathepsin B, lactoferrin, E-selectin, SPINK 1, procalcitonin, S100 proteins, alfa-1-antitrypsin, hs-CRP, malondialdehyde, serum and urine amylase and serum lipase). Serum amylase and lipase rose significantly with the maximum 4 hours after DBE. Serum cathepsin and procalcitonin decreased significantly 4 hours after DBE compared to healthy controls and patients values before DBE. Either serum amylase or lipase 4 hours after DBE did not correlate with any markers before DBE. There was a trend for an association between the number of push-and-pull cycles and procalcitonin and urine amylase 4 hours after DBE; between procalcitonin and alfa-1-antitrypsin, cathepsin and hs-CRP; and between E-selectin and malondialdehyde 4 hours after DBE. We found no laboratory markers determinative in advance those patients in a higher risk of acute pancreatitis after DBE.

Keywords: Acute pancreatitis; Deep enteroscopy; Device assisted endoscopy; Double balloon enteroscopy; Hyperamylasemia; Small intestinal disorders

\section{Introduction}

Double balloon endoscopy (DBE) is a method of enteroscopy that was introduced in $2001(1-3)$.

The system consists of enteroscope and over-tube; both have a soft balloon at their tips. Both balloons can be alternately inflated and deflated by an air balloon-pump controller. DBE is based on a new insertion technique in which these two balloons are operated in combination, and the endoscope is inserted while simultaneously shortening the intestine.

Acute pancreatitis is the most feared complication in oral DBE. Despite a 15-year experience, the causal reason of acute pancreatitis remains uncertain. There are many hypotheses explaining this fact: direct trauma of the pancreas caused by the pressure of an endoscope against the vertebral column, the disorders in microcirculation during the procedure, increase in intraluminal duodenal pressure during enteroscopy caused by inflation of the two balloons, reflux of duodenal fluids into the pancreatic duct, timing of the procedure and others. We published a prospective study concerning this risk (Kopáčová et al. Gastrointest Endosc
2007; 66(6): 1133-1138) (4). In our contemporary project we continue in priority investigation of known or supposed protective and risk factors (rehydration, oral DBE, time of procedure, number of cycles, the depth of intubation, $\mathrm{CO}_{2}$ insufflation) in correlation with serum and urine amylase, lipase and hs-CRP and some possible plasmatic markers of a higher risk of acute pancreatitis (malondialdehyde, procalcitonin, S 100 proteins, cathepsin B, pancreatic secretory trypsin inhibitor (PSTI; also known as serine protease inhibitor Kazal-type 1 (SPINK 1) or tumour-associated trypsin inhibitor (TATI), lactoferrin, E-selectin and alfa-1 antitrypsin (A1AT). Our project assumes the outcome of possibility to identify high risk patients for DBE-associated acute pancreatitis.

As DBE is a lengthy procedure, a large volume of air is usually insufflated leading to significant distension of the small bowel. Indeed, one of the main technical challenges of DBE is the formation of distended bowel loops and acute angulations with increasing amounts of gas intra-luminally. Carbon dioxide $\left(\mathrm{CO}_{2}\right)$, unlike air, is rapidly absorbed from the bowel. Bowel insufflation with $\mathrm{CO}_{2}$, instead of air, enhances patients comfort and decreases the need for sedation 
(5-7). We have used $\mathrm{CO}_{2}$ insufflation in DBE procedures regularly since 2007; since we had no complications with hyperinflation, the comfort of the patient rapidly increased and this type of insufflation is helpful for easier and deeper insertion of the scope, because the absorption of $\mathrm{CO}_{2}$ is 150 -times faster than absorption of air in the bowel. A randomised, double-blind trial showed that insufflation with $\mathrm{CO}_{2}$ is safe, reduces patient discomfort, and significantly improves intubation depth (8).

A combination of water with simethicone is used routinely to do away with bubbles in the intestine. During withdrawal of the endoscope and during therapeutic interventions, spasmolytics might improve visualisation of the small-bowel mucosa by reducing motility of the small bowel $(5,6)$.

A venous access is obtained before the procedure. All patients are monitored during the procedure; oxygen saturation, heart rate, and blood pressure are monitored. Intravenous crystaloids are administered during DBE. Conscious sedation is thought to be sufficient for $\operatorname{DBE}(5,6)$. It seems to be much better in DBE in comparison with general anaesthesia according to our experience. Abdominal pain of the patient is a very important warning signal, and it is necessary to terminate the procedure immediately in that case. Intense pain may be a sign of inadequate pressure on the pancreas and poses a high risk of post-DBE pancreatitis $(4,7,9,10)$. We use small intravenous repetitive doses of midazolam and pentazocine for conscious sedation (batch-wise).

The duration of the procedure and the discomfort for the patient caused by oral passage of the over-tube require deep analgo-sedation. The cost of the procedure is high (the over-tube and balloons are designed for single use). The procedure requires an experienced endoscopist and fluoroscopy, especially at the beginning, during a learning period (11)

\section{Material and Methods}

A total of 117 DBEs in 94 patients were scheduled for our recent study yet (50 men and 44 women, mean age 52 years) under deep conscious sedation (midazolam and pentazocine). The mean time of DBE was $80 \mathrm{~min}$. (range 30-180 min.), the mean number of push-and-pull cycles was 13 (range 1-45). Thirty healthy volunteers without DBE (9 men and 21 women, mean age 41 years) created a control group.

The DBE investigations were performed standardly by an oral approach in our in-patients. The choice of the endoscope (therapeutic or diagnostic) was based on the indication. Over-tube was used in all cases. The conscious sedation was used (midazolam, pentazocine). Crystaloids were given intravenously during the DBE (depending on the time of the procedure $500-1,000 \mathrm{~mL} \mathrm{F1/1;500} \mathrm{mL} \mathrm{per}$ hour).

Blood and urine samples were collected before the DBE procedure and 4 and 24 hours after the DBE. Besides standard routine investigations (amylases, lipase, hs-CRP), several laboratory markers were also investigated, their list is provided bellow. Abdominal pain was evaluated using a three-step scale (no pain, moderate and significant pain).

Hs-CRP was quantified using imunoturbidimetry on Roche/Hitachi MODULAR P (Roche, Germany), detection range $0-5 \mathrm{mg} / \mathrm{L}$.

Malondialdehyde was measured using photometry spectrophotometer Secomam S.500P (TrigonPlus, Czech Republic), detection range $0.26-1.07 \mu \mathrm{mol} / \mathrm{L}$.

Procalcitonin was assessed by means of enzyme-linked immunosorbent assay kit (ELISA, USCN Life Science Inc., USA), detection range $31.2-2,000 \mathrm{pg} / \mathrm{mL}$.

S 100 proteins were quantified using electrochemiluminiscence (ECLIA) - sandwich reaction on automatic immunoanalyzer Elecsys 2010 (Roche, Germany), detection range $<0.105 \mu \mathrm{g} / \mathrm{L}$.

Cathepsin B was measured using enzyme-linked immunosorbent assay kit (ELISA, USCN Life Science Inc., USA), detection range $0.312-20 \mathrm{ng} / \mathrm{mL}$.

Serine peptidase inhibitor Kazal type 1 (SPINK 1) was quantified using enzyme-linked immunosorbent assay kit (ELISA, USCN Life Science Inc., USA), detection range $1.56-100 \mathrm{ng} / \mathrm{mL}$.

Lactoferrin was analyzed by means of enzyme-linked immunosorbent assay kit (ELISA, USCN Life Science Inc., USA), detection range $0.312-20 \mathrm{ng} / \mathrm{mL}$.

E-selectin was measured using enzyme-linked immunosorbent assay kit (ELISA, USCN Life Science Inc., USA), detection range 39-2,500 $\mathrm{pg} / \mathrm{mL}$.

Alfa-1-antitrypsine (A1AT) using immunoturbidimetry on Roche/Hitachi MODULAR P (Roche, Germany), detection range $0.9-2.0 \mathrm{~g} / \mathrm{L}$.

Laboratory markers were also investigated in a control group of clinically healthy volunteers without DBE.

\section{Study approval and confidentiality of data obtained}

The project received a full approval from the local Ethics Committee (joint committee of the University Teaching Hospital and Faculty of Medicine at Hradec Králové). For all data obtained, all personal identification information was deleted in compliance with the laws for the protection of confidentiality of the Czech Republic.

\section{Results}

Data was processed by means of statistical software for these analyses (SigmaStat; Jandel Corp., Erkrath, Germany), using descriptive statistics, paired t-test, Mann-Whitney rank sum test and Pearson product moment correlation.

We investigated supposed protective and risk factors (rehydration, oral DBE, time of procedure, number of cycles, the depth of intubation, $\mathrm{CO}_{2}$ insufflation) in correlation with serum and urine amylase, lipase and hs-CRP and some possible plasmatic markers of a higher risk of acute pancreatitis 
(malondialdehyde, procalcitonin, S 100 proteins, cathep$\sin$ B, pancreatic secretory trypsin inhibitor (PSTI; also known as serine protease inhibitor Kazal-type 1 (SPINK 1) or tumour-associated trypsin inhibitor (TATI), lactoferrin, E-selectin and alfa-1 antitrypsin (A1AT) in 117 DBEs (3 times - basal, after DBE in 4 and 24 hours) and 30 volunteers (only basal).

The age range of volunteers and patients were slightly different; mean 44 years (range 28-64 years) in healthy volunteers and 52 years (18-84) in patients. We did not find any correlations of followed parameters with age, so we find this difference insignificant.

We find only correlation of age and pain after DBE. The patients without pain $(n=89)$ were significantly older than patients with moderate $(n=22 ; p=0.038)$ or significant $(n=6$; $\mathrm{p}=0.020$ ) pain. Duration of procedure was significantly shorter in patients without pain $(\mathrm{n}=89)$ than in patients with moderate $(n=22 ; p=0.041)$ or significant pain $(n=6 ; p=0.007)$.

We have not recorded any DBE-associated acute pancreatitis in this series of 117 DBEs.

In healthy controls, serum amylase correlated with serum lipase $(r=0.514 ; p=0.004)$, alfa-1-antitrypsin correlated with hs-CRP ( $\mathrm{r}=0.503 ; \mathrm{p}=0.005)$, serum cathepsin correlated significantly with E-selectin $(r=0.467 ; p=0.009)$ and with serum lipase $(r=0.495 ; \mathrm{p}=0.005)$.

In our 117 patients serum amylase and lipase rose significantly with the maximum 4 hours after DBE $(p<0.001$ and $\mathrm{p}<0.001)$ while in hs-CRP we found maximum in 24 hours after DBE $(p<0.001)-$ see Figures $1-4$. There was a significant correlation between significant pain and serum amylase $(\mathrm{p}<0.039)$ and lipase $(\mathrm{p}<0.005)$.

Serum cathepsin and procalcitonin decreased significantly 4 hours after DBE compared to healthy controls and patients' values before DBE ( $p=0.018$ and $p=0.031)$; see Table 1 for details. There was a trend for an association between number of push-and-pull cycles and procalcitonin $(\mathrm{r}=$ $-0.384 ; \mathrm{p}=0.011)$ and urine amylase $(\mathrm{r}=0.313 ; \mathrm{p}=0.043)$ 4 hours after DBE; between procalcitonin and alfa-1-anti$\operatorname{trypsin}(r=0.358 ; p=0.021)$, cathepsin $(r=0.362 ; p=0.020)$ and hs-CRP ( $\mathrm{r}=0.358 ; \mathrm{p}=0.021)$; and between E-selectin and malondialdehyde $(r=0.364 ; p=0.019) 4$ hours after DBE. Either serum amylase or lipase 4 hours after DBE did not correlate with any markers before DBE.

We did not identify any marker to recognise high risk patients for DBE-associated acute pancreatitis. As the main risk factor was identified time of procedure (number of push and pull cycles) and the pain during procedure.

\section{Discussion}

In general, acute pancreatitis is a very heterogenous group of different aetiology and pathogenesis. Several predisposing factors, including genetic ones, were identified. The aim of our current project was to investigate several laboratory markers to identify patients in a higher risk of DBE-associated acute pancreatitis. Some interesting findings were revealed but no clear "high-risk" factor was identified. Procalcitonin surprisingly decreased after DBE. This decline was consistent and statistically significant. Explanation for this phenomenon is difficult. Procalcitonin, a propeptide of calcitonin, is an acute phase reactant that has been investigated extensively as an early marker of severe acute pancreatitis and/or its infective complications (12). This significant fall of procalcitonin in our study might be at least partly explained by distribution changes due to "preventive" saline infusion during DBE to secure proper

Tab. 1: Laboratory investigations in healthy control volunteers and in patients before and after double balloon enteroscopy.

\begin{tabular}{|l|c|c|c|c|}
\hline Parameter $(\mathrm{Mean} \pm \mathrm{StdDev})$ & Controls & DBE-0h & DBE-4h & DBE-24h \\
\hline Cathepsin B $(\mathrm{pg} / \mathrm{L})$ & $14.9 \pm 20.0$ & $10.1 \pm 14.9$ & $7.2 \pm 12.9$ & $9.1 \pm 14.8$ \\
\hline Lactoferrin $(\mathrm{pg} / \mathrm{L})$ & $495 \pm 413$ & $725 \pm 553$ & $708 \pm 711$ & $840 \pm 824$ \\
\hline E-selectin $(\mu \mathrm{g} / \mathrm{L})$ & $27433 \pm 15861$ & $26865 \pm 18721$ & $23274 \pm 16465$ & $25973 \pm 17074$ \\
\hline SPINK 1 $(\mathrm{pg} / \mathrm{L})$ & $46.7 \pm 21.6$ & $43.6 \pm 43.7$ & $43.6 \pm 52.6$ & $37.7 \pm 34.9$ \\
\hline Procalcitonin $(\mu \mathrm{g} / \mathrm{L})$ & $71.7 \pm 19.4$ & $121.6 \pm 118.6$ & $67.6 \pm 54.9$ & $92.3 \pm 81.9$ \\
\hline S100 $(\mu \mathrm{g} / \mathrm{L})$ & $0.05 \pm 0.02$ & $0.05 \pm 0.04$ & $0.07 \pm 0.08$ & $0.05 \pm 0.03$ \\
\hline Alfa-1-antitrypsin $(\mathrm{g} / \mathrm{L})$ & $1.37 \pm 0.28$ & $1.63 \pm 0.43$ & $1.63 \pm 0.43$ & $1.52 \pm 0.42$ \\
\hline hs-CRP $(\mathrm{mg} / \mathrm{L})$ & $1.16 \pm 1.69$ & $3.02 \pm 8.90$ & $8.13 \pm 14.97$ & $6.15 \pm 11.50$ \\
\hline Malondialdehyde $(\mu \mathrm{mol} / \mathrm{L})$ & $0.27 \pm 0.19$ & $0.34 \pm 0.28$ & $0.26 \pm 0.17$ & $0.28 \pm 0.21$ \\
\hline Serum amylase $(\mu \mathrm{kat} / \mathrm{L})$ & $1.02 \pm 0.33$ & $0.99 \pm 0.37$ & $3.65 \pm 2.96$ & $1.80 \pm 1.29$ \\
\hline Urine amylase $(\mu \mathrm{kat} / \mathrm{L})$ & $0.83 \pm 0.87$ & $1.77 \pm 1.55$ & $7.41 \pm 10.64$ & $4.03 \pm 3.75$ \\
\hline Serum lipase $(\mu \mathrm{kat} / \mathrm{L})$ & $0.67 \pm 0.23$ & $0.72 \pm 0.55$ & $4.40 \pm 5.86$ & $1.01 \pm 1.13$ \\
\hline
\end{tabular}

Notes: DBE-0h: investigation before double balloon enteroscopy. DBE-4h: investigation 4 hours after double balloon enteroscopy completed. DBE-24h: investigation 24 hours after double balloon enteroscopy completed. 


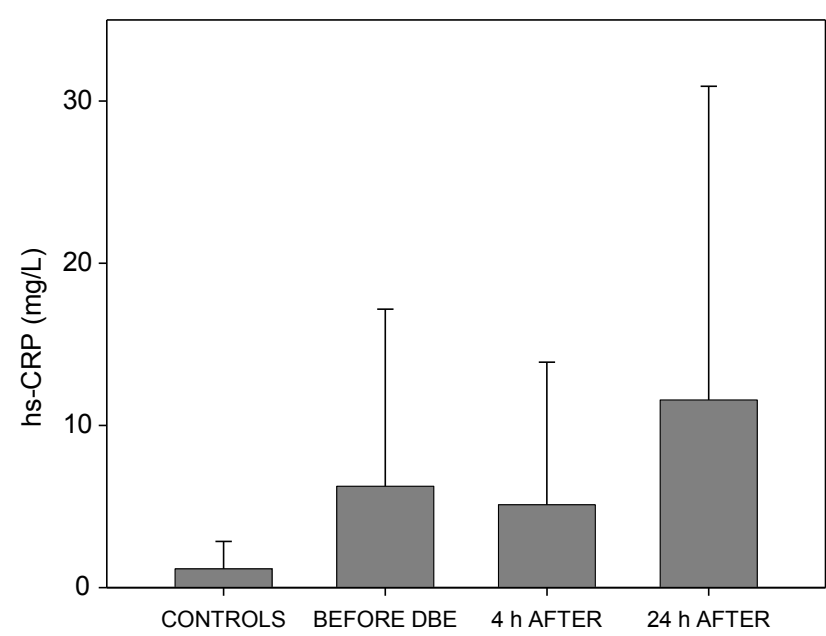

Fig. 1: Serum hs-CRP (mean + standard deviation) in healthy control subjects and in patients before double balloon enteroscopy (DBE- $0 \mathrm{~h}$ ) and 4 hours and 24 hours after double balloon enteroscopy was completed (DBE-4h; DBE-24h).

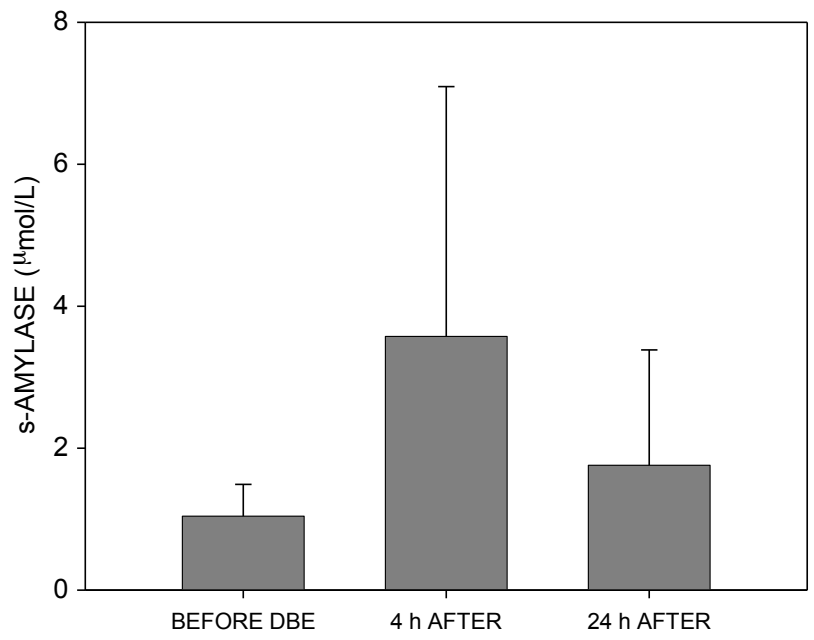

Fig. 3: Urine amylase (mean + standard deviation) in patients before double balloon enteroscopy (DBE-0h) and 4 hours and 24 hours after double balloon enteroscopy was completed (DBE-4h; DBE-24h).

microcirculation in the pancreas. Our results suggest that DBE does not stimulate proinflammatory cascade.

DBE has been reported as a safe endoscopic technique (13), the number of severe complications being mentioned ranging from 0 to $1.4 \%(14-16)$. However, abdominal pain lasting 1-2 days occurred in $9 \%$ of patients in one study (17) or even in $20 \%$ according to the another one (14). Abdominal discomfort slaking within 72 hours was reported in 50\% of patients after a DBE procedure (18).

In some series on DBE, no complications during or after DBE were reported (19-27). But reading these articles

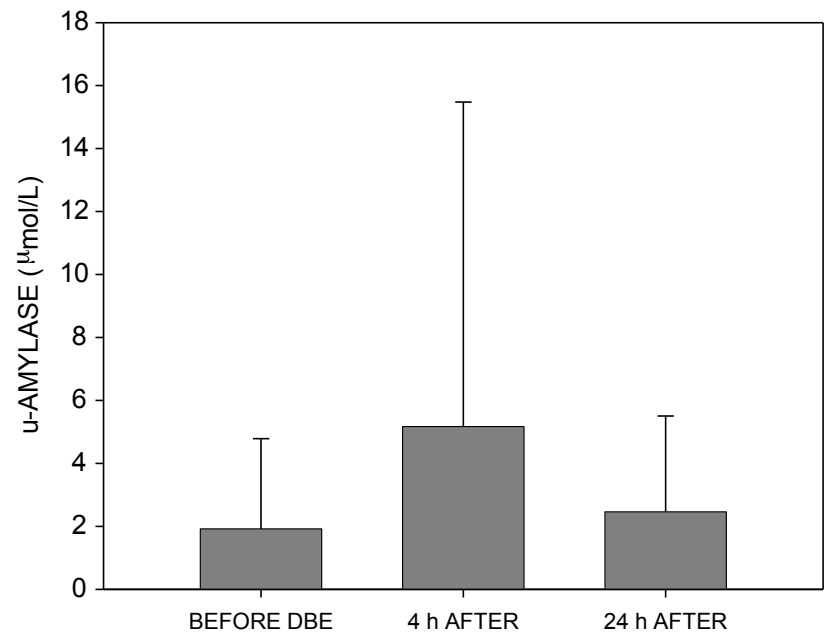

Fig. 2: Serum amylase (mean + standard deviation) in patients before double balloon enteroscopy (DBE-0h) and 4 hours and 24 hours after double balloon enteroscopy was completed (DBE-4h; DBE-24h).

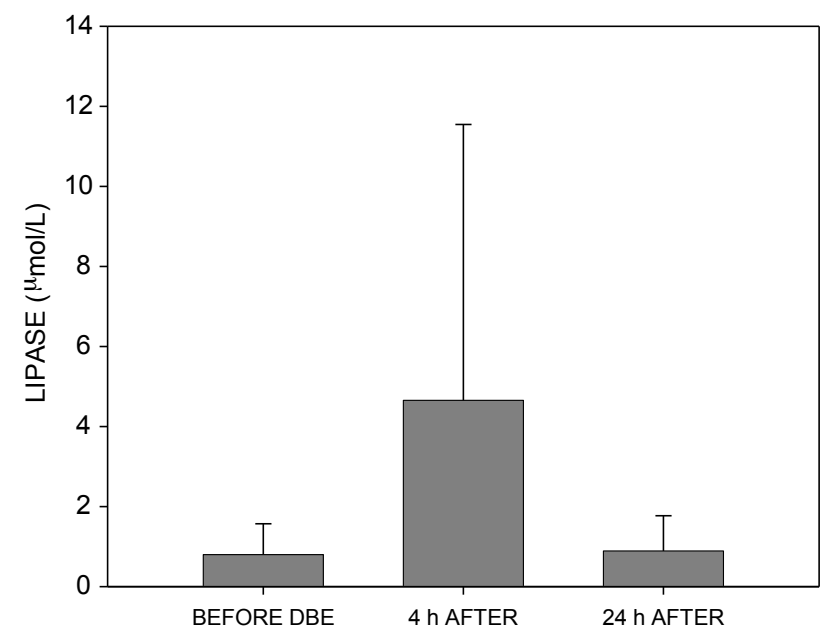

Fig. 4: Serum lipase (mean + standard deviation) in patients before double balloon enteroscopy (DBE-0h) and 4 hours and 24 hours after double balloon enteroscopy was completed (DBE-4h; DBE24h).

carefully, one will find in Pata et al. (25) 13\% oral bleeding, $2 \%$ broken tooth and $2 \%$ respiratory depression due to aspiration. Moreover, some patients in the initial setting of 36 patients developed pancreatic-type abdominal pain and under prospective following 6 of next 48 patients $(12.5 \%)$ developed acute pancreatitis and another 6 hyperamylasemia (25). Similarly in a large multicentre study of Domagk et al. (26) no adverse events are declared in the abstract, but mean pain one hour after examination on the $100 \mathrm{~mm}$ visual scale was 12.2 and mean pain after 24 hours was 2.4 (26). Are there really difference in complication rate be- 
tween particular endoscopy units or the difference is only in the investigation of the patient after endoscopy and his/ her follow up?

Major (severe) complications such as pancreatitis, bleeding and perforation have been reported in approximately $1 \%$ of all diagnostic DBE whereas the complication rate for therapeutic procedures is about $5 \%(28)$.

Minor complications are sore throat, oedema of the uvula, and abdominal discomfort. Some casuistic complications were described in the literature: balloon dislocation, segmental enteritis after argon plasma coagulation (29), intestinal necrosis after epinephrine injection (30), paralytic ileus (31) etc. The complication rate of diagnostic procedures is low $(0.4-0.8 \%)$ according to the literature $(32-35)$. The overall complication rate of therapeutic DBE is about 3-4\%. However, difficult therapeutic endoscopic procedures (e.g. resection of large polyps) may increase the risk up to $10 \%$ $(5,6,32-34)$. The perforation rate is significantly elevated in patients with postsurgical anatomy undergoing diagnostic retrograde DBE examinations (36).

The overall complication rate is reported in about $1.7 \%$ of patients in an international multicentre survey in 2,362 DBE procedures. The complications were rated minor in $0.9 \%$, moderate in $0.3 \%$ and severe in $0.6 \%$ of procedures. The complication rate is significantly higher in therapeutic procedures in comparison with diagnostic ones ( $4.3 \%$ versus $0.8 \%)$. An exception to this rule is acute pancreatitis, the most common complication in diagnostic DBE procedures. Acute pancreatitis was reported in $0.3 \%$ of DBEs $(32,37)$.

A report from the National German DBE Register showed an overall complication rate of $1.2 \%$ in a large series of 3,894 DBE procedures. The incidence of acute pancreatitis was also $0.3 \%$ in this report $(33,34)$.

A publication by May et al. (29) evaluated acute complication rate of $\mathrm{DBE}$ in 353 patients. Only therapeutic procedures are evaluated with a complication rate of $3.4 \%$. No acute pancreatitis was reported (29).

On the other hand, a recent prospective study was published by Zepeda-Gómez et al. with incidence of acute pancreatitis of 3\% (38). According to Pata et al. pancreatitis after DBE was observed in $12.5 \%$ in their series (39).

In general, DBE is associated with a higher complication rate compared with standard endoscopic procedures (36).

A complication of endoscopy is defined as any event that negatively changes the health status of the patient, and that occurs during the 30-day period after the investigation. Complications are usually categorised as minor when requiring up to 3 days of hospitalisation, moderate when requiring 3-10 days and major or severe when requiring more than 10 days of hospitalisation, and/or an endoscopic, radiological or surgical intervention, and/or contribute to the death of the patient $(32,40)$. Procedure-related mortality is defined as mortality within 30 days of DBE (32).

It is possible categorized into three groups: 1) those common to other endoscopic techniques (perforation, bleeding), 2) related to sedation administered during the procedure (respiratory depression, aspiration, pneumonia) and 3) complications specifically associated with DBE (acute pancreatitis) $(5,6,28)$. The complication rate is about $9 \%$ for minor complications and less than $1 \%$ for major ones (28). The most discussed complication is acute pancreatitis after $\operatorname{DBE}(35,37)$. In diagnostic procedures via the anterograde approach, acute pancreatitis is the most common and most severe complication $(5,6)$. The very first post-DBE acute pancreatitis was reported by Honda et al. in 2006 (41).

The causal mechanism of post-DBE acute pancreatitis is uncertain; there are several theories in the literature: direct trauma of the pancreas caused by pressure of the endoscope against the vertebral column in the oral procedure, the disorders in microcirculation during the procedure, increase in intraluminal duodenal pressure during the endoscopic procedure caused by inflation of the two balloons, reflux of duodenal fluids into the pancreatic duct leading to acute pancreatitis. No one of these hypotheses brought the total explanation of the pathogenesis $(9,10,28)$. Whereas the increase of amylase and lipase levels after DBE occurs in the significant percentage of patients $(30-50 \%)$ when systematically measured $(25,38,42)$.), the rate of post-DBE acute pancreatitis is much lower, about $0.2-0.5 \%(25,42)$. Hyperamylasemia and hyperlipasemia are common conditions after DBE. Asymptomatic hyperamylasemia may occur in nearly half of DBE procedures $(4,9,10,41,43-45)$. The incidence of hyperamylasemia and pancreatitis after single-balloon enteroscopy or spiral enteroscopy seems to be comparable to that after DBE (45-47).

Hyperamylasemia and hyperlipasemia after DBE are usually asymptomatic and do not present the immediate risk factor of acute pancreatitis $(9,10)$. The only identified factors increasing risk of post-procedure acute pancreatitis are duration of the procedure (i.e. number of push-pull cycles) and interval time between the first and the second inflation of balloons according to some authors $(9,10,39)$. Learning curve seems to be another risk factor; about 50 procedures are needed to acquire enough experience (28). We had four cases of acute pancreatitis among our first 267 oral DBE procedures; it was number 24, 50, 57 and 256 in chronological order. Classification system for acute pancreatitis was discussed in our previous paper (10).

Our centre has long-term experience (since 1994) with both push-enteroscopy (48) and intra-operative enteroscopy $(10,49-51)$. We have never registered acute pancreatitis as a complication of either push-enteroscopy or intra-operative enteroscopy in our setting. However, acute pancreatitis as such a complication of push-enteroscopy, caused by an overtube, was described previously by other authors (52). Acute pancreatitis was even described after uneventful upper and lower gastrointestinal endoscopy (53-55). Blackwood et al detected asymptomatic hyperamylasuria in $6.6 \%$ of patients undergoing gastrointestinal endoscopy (56).

Pelletier et al. (57) studied the prevalence of hyperamylasemia 2 hours and 24 hours after upper gastrointestinal endoscopy in 50 consecutive patients. In the 2-hour sample, 
hyperamylasemia was observed in nine patients $(18 \%)$, in the 24-hour sample in five patients. Pelletier et al. conclude that the cause of hyperamylasemia may be due to hypersalivation during the procedure (57). In our opinion, hypersalivation cannot affect the serum amylase level in such a way (most of the saliva runs out of the mouth during endoscopy and is not swallowed). Furthermore, it cannot affect abdominal pain or pancreatic lipase elevation (9).

There have been about 100 published cases of post-DBE acute pancreatitis on PubMed so far $(10,14,32-37,39,41$, $44,46,58-62,64)$.

In agreement with the Dutch study, we believe that post-DBE pancreatitis is underestimated in retrospective studies on an outpatient basis. It is hard to say how many patients with self-limited abdominal post-DBE pain had mild acute pancreatitis because of inadequate follow-up. Especially retrospective questionnaire-based surveys might be at risk from an inaccurate report or inclusion bias (59). As the distinction between clinically mild pancreatitis and hyperamylasemia with transient abdominal discomfort is somehow arbitrary, it seems likely that the underdiagnosis of post-DBE pancreatitis might have occurred, especially in out-patients. In our opinion, mechanical stress on the pancreas seems to be presumable. Traumatic injury of the pancreas seems to be the main cause of acute pancreatitis $(14,41,44$, 59, 64).

Another important point is prevention of post-DBE pancreatitis. We use parenteral hydration during the oral procedure and after it. The usual dose is 1 litre of saline solution during a 2-hour procedure. We presume that hydration could improve blood supply to the splanchnic region, and secure pancreatic microcirculation and post-procedure recovery. The use of proteinase inhibitors such as gabexate mesylate in the prevention of post-endoscopic pancreatitis has been disappointing $(65,66)$. There are some studies of intravenous nitroglycerine $(67)$, ulinastatin $(68,69)$, somatostatin $(65,66,70,71)$, rectal diclofenac (68), and other drugs in prevention of post-procedure pancreatitis, but the results are not significant.

\section{Conclusions}

Our current results support our previous hypothesis that endoscope-induced mechanical straining during DBE is the most important factor responsible for the increase of amylase and lipase or even for progression to acute pancreatitis. We found no laboratory markers that would identify in advance those patients in a higher risk.

Acute pancreatitis is a feared complication of oral DBE (100 cases of acute pancreatitis have been described in the literature so far).

Acute pancreatitis is the most common severe complication seen after diagnostic oral DBE (complications of therapy itself prevail in therapeutic procedures).

Hyperamylasemia and elevation of pancreatic lipase after DBE seems to be a common condition. Association with acute pancreatitis is supposed to be possible, but not obligatory.

The complication rate of acute pancreatitis is reported at about $0.3 \%$ of DBEs according to large studies, almost solely after the oral DBE. Drawbacks and possible bias of those studies are that they are mostly retrospective, a substantial part of DBEs were performed on an outpatient basis and the follow-up of these patients was inadequate.

In all patients with abdominal pain during the procedure and/or after the oral DBE, diagnosis of acute pancreatitis should be considered and treatment should be provided in good time, identically as in post-ERCP pancreatitis.

Conscious sedation seems to be more favourable in comparison with general anaesthesia due to monitoring of the patient's pain during the procedure.

Intense pain during the procedure may be a sign of inadequate pressure on the pancreas and pose a high risk of post-DBE pancreatitis.

$\mathrm{CO}_{2}$ insufflation during DBE is highly recommended as it prevents over-inflation of the small bowel, however, possible preventive relationship to post-DBE pancreatitis has not been determined yet.

\section{Acknowledgements}

This study was supported by research project IGA NT 13414-4/2012 from Ministry of Health, Czech Republic.

\section{References}

1. Yamamoto H, Sekine Y, Sato Y, et al. Total enteroscopy with a nonsurgical steerable double-balloon method. Gastrointestinal Endoscopy 2001; 53(2): 216-220.

2. Yamamoto H, Sugano K. A new method of enteroscopy - the double-balloon method. Can J Gastroenterol 2003; 17(4): 273-274.

3. Yamamoto H, Yano T, Kita H, Sunada K, Ido K, Sugano K. New system of double-balloon enteroscopy for diagnosis and treatment of small intestinal disorders. Gastroenterology 2003; 125(5): 1556-1557.

4. Kopacova M, Rejchrt S, Tacheci I, Bures J. Hyperamylasemia of uncertain significance associated with oral double-balloon enteroscopy. Gastrointest Endosc 2007; 66(6): 1133-1138.

5. Pohl J, Delvaux M, Ell C, Gay G, May A, Mulder CJ, Pennazio M, Perez-Cuadrado E, Vilmann P and ESGE Clinical Guidelines Committee. European Society of Gastrointestinal Endoscopy (ESGE) guidelines: flexible enteroscopy for diagnosis and treatment of small-bowel diseases. Endoscopy 2008; 40(7): 609-618.

6. Pohl J, Blancas JM, Cave D, et al. Consensus report of the 2nd International Conference on double balloon endoscopy. Endoscopy 2008; 40(2): 156-160.

7. Kopacova M, Tacheci I, Rejchrt S, Bures J. Peutz-Jeghers syndrome: Diagnostic and therapeutic approach. World J Gastroenterol 2009; 15(43): 5397-5408.

8. Domagk D, Bretthauer M, Lenz P, et al. Carbon dioxide insufflations improves intubation depth in double-balloon enteroscopy; a randomized, controlled, double-blind trial. Endoscopy 2007; 39(12): 1064-1067.

9. Kopacova M, Rejchrt S, Tacheci I, Bures J. Association of hyperamylasemia and longer duration of peroral double-balloon enteroscopy: present and future. Gastrointest Endosc 2008; 68(4): 811-812.

10. Kopacova M, Tacheci I, Rejchrt S, Bartova J, Bures J. Double balloon enteroscopy and acute pancreatitis. World J Gastroenterol 2010; 16(19): 2331-2340.

11. Gay G, Delvaux M. Small-bowel endoscopy. Endoscopy 2006; 38(1): 22-26.

12. Matull WR, Pereira SP, O'Donohue JW. Biochemical markers of acute pancreatitis. J Clin Pathol 2006; 59(4): 340-344.

13. Yamamoto H, Kita H. Enteroscopy. J Gastroenterol 2005; 40(6): 555-562.

14. Heine GD, Hadithi M, Groenen MJ, Kuipers EJ, Jacobs MA, Mulder CJ. Double-balloon enteroscopy: indications, diagnostic yield, and complications in a series of 275 patients with suspected small-bowel disease. Endoscopy 2006; 38(1): $42-48$.

15. Yamamoto H, Kita H, Sunada K, et al. Clinical outcomes of double-balloon endoscopy for the diagnosis and treatment of small-intestinal diseases. Clin Gastroenterol Hepatol 2004; 2(11): 1010-1016. 
16. Mönkemüller K, Weigt J, Treiber G, et al. Diagnostic and therapeutic impact of double-balloon enteroscopy. Endoscopy 2006; 38(1): 67-72.

17. Ell C, May A, Nachbar L, et al. Push-and-pull enteroscopy in the small bowel using the double-balloon technique: results of a prospective European multicenter study. Endoscopy 2005; 37(7): 613-616.

18. Jones BH, Harrison ME, Fleischer DE, Maltby NL, Leighton JA. Double balloon enteroscopy: New information and limitations defined. Gastrointest Endosc 2005; 61: AB229.

19. May A, Nachbar L, Ell C. Double-balloon enteroscopy (push-and-pull enteroscopy) of the small bowel: feasibility and diagnostic and therapeutic yield in patient with suspected small bowel disease. Gastrointest Endosc 2005; 62(1): 62-70.

20. May A, Manner H, Aschmoneit I, Ell C. Prospective, cross-over, single-center trial comparing oral double-balloon enteroscopy and oral spiral enteroscopy in patients with suspected small-bowel vascular malformations. Endoscopy 2011; 43(6): 477-483

21. Prachayakul V, Deesomsak M, Aswakul P, Leelakusolvong S. The utility of single-balloon enteroscopy for the diagnosis and management of small bowel disorders according to their clinical manifestations: a retrospective review. BMC Gastroenterology 2013; 13: 103.

22. Su MY, Liu NJ, Hsu CM, Chiu CT, Chen PC, Lin CJ. Double balloon enteroscopy - the last blind-point of the gastrointestinal tract. Dig Dis Sci 2005; 50(6): 1041-1045.

23. Matsumoto T, Esaki M, Moriyama T, Nakamura S, Iida M. Comparison of capsule endoscopy and enteroscopy with the double-balloon method in patients with obscure bleeding and polyposis. Endoscopy 2005; 37(9): 827-832

24. Wu CR, Huang LY, Song B, Yi LZ, Cui J. Application of double-balloon enteroscopy in the diagnosis and therapy of small intestinal diseases. Chin Med J 2007; 120(23): 2075-2080.

25. Pata C, Akyüz U, Erzin Y, Mercan A. Double-balloon enteroscopy: The diagnosis and management of small bowel diseases. Turk J Gastroenterol 2010; 21(4): 353-359.

26. Domagk D, Mensink P, Aktas H, et al. Single- vs. double-balloon enteroscopy in small-bowel diagnostics: a randomized multicenter trial. Endoscopy 2011; 43(6): $472-476$

27. Akarsu M, Ugur Kantar F, Akpinar H. Double-balloon endoscopy in patients with Peutz-Jeghers syndrome. Turk J Gastroenterol 2012; 23(5): 496-502.

28. Rondonotti E, Sunada K, Yano T, Paggi S, Yamamoto H. Double-balloon endoscopy in clinical practice: Where are we now? Dig Endosc 2012; 24(4): 209-219.

29. May A, Nachbar L, Pohl J, Ell C. Endoscopic interventions in the small bowe using double balloon enteroscopy: Feasibility and limitations. Am J Gastroenterol 2007; 102(3): 527-535.

30. Yen HH, Chen YY, Su WW, Soon MS, Lin YM. Intestinal necrosis as a complication of epinephrine injection therapy during double-balloon enteroscopy. Endoscopy 2006; 38(5): 542 .

31. Attar A, Maissiat E, Sebbagh V, Cellier C, Wind P, Bénamouzig R. First case of paralytic intestinal ileus after double balloon enteroscopy. Gut 2005; 54(12): $1823-1824$

32. Mensink PB, Haringsma J, Kucharzik T, et al. Complications of double balloon enteroscopy: a multicentric survey. Endoscopy 2007; 39(7): 613-615.

33. Möschler O, May A, Müller MK, Ell C and DBE-Studiengruppe Deutschland. Complications in double-balloon enteroscopy; results of the German DBE register. Z Gastroenterol 2008; 46(3): 266-270.

34. Möschler O, May A, Müller MK, Ell C and DBE-Studiengruppe Deutschland, Complicatons and more: Results of the German prospectiove DBE-database by the German DBE Study Group. Gastrointest Endosc 2008; 67: AB262.

35. Eisen GM, Schreiner M. Small-bowel endoscopy. Endoscopy 2007; 39(2): $113-117$.

36. Gerson LB, Tokar J, Chiorean M, et al. Complications associated with double balloon enteroscopy at 9 US centers. Clin Gastroenterol Hepatol 2009; 7(11) $1177-1182$.

37. Mensink PB. Complications of double balloon enteroscopy. Tech Gastrointest Endosc 2008; 10: 66-69.

38. Zepeda-Goméz S, Barreto-Zuňiga R, Ponce-de-León S, et al. Risk of hyperamylasemia and acute pancreatitis after double-balloon enteroscopy: a prospective study. Endoscopy 2011; 43(9): 766-770.

39. Pata C, Akyüz U, Erzin Y, Mutlu N, Mercan A, Dirican A. Post-procedure elevated amylase and lipase levels after double-balloon enteroscopy: Relations with the double-balloon technique. Dig Dis Sci 2010; 55(7): 1982-1988.

40. Cotton PB, Lehman G, Vennes J, et al. Endoscopic sphincterotomy complications and their management: an attempt at consensus. Gastrointest Endosc 1991; 37(3): 383-393.

41. Honda K, Mizutani T, Nakamura K, et al. Acute pancreatitis associated with peroral double-balloon enteroscopy: A case report. World J Gastroenterol 2006; 12(11): $1802-1804$

42. Xin L, Liao Z, Jiang YP, Li ZS. Indications, detectability, positive findings, total enteroscopy, and complications of diagnostic double-balloon endoscopy: a systematic review of data over the first decade of use. Gastrointest Endosc 2011; 74(3) 563-570.

43. Pennazio M. Small-bowel endoscopy. Endoscopy 2008; 40(10): 835-842.
44. Honda K, Itaba S, Mizutani T, et al. An increase in the serum amylase level in patients after peroral double-balloon enteroscopy: an association with the development of pancreatitis. Endoscopy 2006; 38(10): 1040-1043.

45. Mönkemüller K, Olano C, Fry LC, Ulbricht LJ. Small-bowel endoscopy. Endoscopy $2009 ; 41(10): 872-877$.

46. Aktas H, de Rider L, Haringsma J, Kuipers EJ, Mensink PB. Complications of single-balloon enteroscopy: a prospective evaluation of 166 procedures. Endoscopy 2010; 42(5): 365-368.

47. Teshima CW, Aktas H, Kuipers EJ. Mensink PB. Hyperamylasemia and pancreatitis following spiral enteroscopy. Can J Gastroenterol 2012; 26(9): 603-606.

48. Bures J, Rejchrt S, (2001). Enteroscopy. In J. Bures, S. Rejchrt et al. Small Bowel Investigation \& Atlas of Enteroscopy (pp. 480). Praha, Grada Publishing.

49. Kopacova M, Bures J, Rejchrt S, et al. Intraoperative enteroscopy-personal experience from 1995 to 2002 (Article in Czech). Cas Lek Cesk 2003; 142(5): 303-306.

50. Kopacova M, Bures J, Vykouril L, et al. Intraoperative enteroscopy. Ten years' experience at a single tertiary center. Surg Endosc 2007; 21(7): 1111-1116.

51. Kopacova M, Tacheci I, Koudelka J, Kralova M, Rejchrt S, Bures J. A new approach to blue rubber bleb nevus syndrome: the role of capsule endoscopy and intra-operative enteroscopy. Pediatr Surg Int 2007; 23(7): 693-697.

52. Gay G, Pennazio M, Delmotte JS, Rossini EP, (1998). Push enteroscopy. In F.P. Rossini, G. Gay, eds. Atlas of Enteroscopy (pp. 43-50). Milan, Springer Verlag.

53. Nevins AB, Keeffe EB. Acute pancreatitis after gastrointestinal endoscopy. J Clin Gastroenterol 2002; 34(1): 94-95.

54. Deschamps JP, Allemand H, Janin Magnificat R, Camelot G, Gillet M, Carayon P. Acute pancreatitis following gastrointestinal endoscopy without ampullary cannulation. Endoscopy 1982; 14(3): 105-106.

55. Thomas AW, Mitre RJ. Acute pancreatitis as a complication of colonoscopy. J Clin Gastroenterol 1994; 19(2): 177-178.

56. Blackwood WD, Vennes JA, Silvis SE. Post-endoscopy pancreatitis and hyperamylasemia. Gastrointest Endosc 1973; 20(2): 56-58.

57. Pelletier G, Nee N, Brivet M, Etienne JP, Lemonnier A. Upper gastrointestinal endoscopy. An unrecognized cause of hyperamylasemia. Dig Dis Sci 1987; 32(3) 254-256.

58. Groenen MJ, Moreels TG, Orlent H, Haringsma J, Kuipers EJ. Acute pancreatitis after double-balloon enteroscopy: an old pathogenetic theory revisited as a result of using a new endoscopic tool. Endoscopy 2006; 38(1): 82-85.

59. Jarbandhan SV, van Weyenberg SJ, van der Veer WM, Heine DG, Mulder CJ, Jacobs MA. Double balloon endoscopy associated pancreatitis: A description of six cases. World J Gastroenterol 2008; 14(5): 720-724.

60. Zhong J, Ma G, Zhang C, et al. A retrospective study of the application on double-balloon enteroscopy in 378 patients with suspected small-bowel diseases. Endoscopy 2007; 39(3): 208-215.

61. Decker GA, Leighton JA, Harrison ME, et al. New technology, new complications: pancreatitis complicating double-balloon enteroscopy. Gastroenterol Hepatol 2007; 3(12): 920-924.

62. Matsushita M, Shimatani M, Uchida K, Okazaki K. Mechanism of acute pancreatitis after peroral double-balloon enteroscopy. Endoscopy 2007; 39(5): 480.

63. Aktas H, Mensink PB, Haringsma J, Kuipers EJ. Low incidence of hyperamylasemia after proximal double-balloon enteroscopy: has the insertion technique improved? Endoscopy 2009; 41(8): 670-673.

64. Sunada K, Yamamoto H. Double-balloon endoscopy: past, present and future. J Gastroenterol 2009; 44(1): 1-12.

65. Andriulli A, Clemente R, Solmi L, et al. Gabexate or somatostatin administration before ERCP in patients at high risk for post-ERCP pancreatitis: a multicenter, placebo-controlled, randomized clinical trial. Gastrointest Endosc 2002; 56(4) $488-495$.

66. Andriulli A, Caruso N, Quitadamo M, et al. Antisecretory vs. antiproteatic drugs in the prevention of post-ERCP pancreatitis: the evidence-based medicine derived from a meta-analysis study. J Pancreas 2003; 4(1): 41-48.

67. Beauchant M, Ingrand P, Favriel JM, et al. Intravenous nitroglycerin for prevention of pancreatitis after therapeutic endoscopic retrograde cholangiography: a randomized, double-blind, placebo-controlled multicenter trial. Endoscopy 2008; 40(8): 631-636.

68. Hoogerwerf WA. Pharmacological management of pancreatitis. Curr Opin Pharmacol 2005; 5(6): 578-582.

69. Itaba S, Nakamura K, Aso A, et al. Prospective, randomized, double-blind, placebo-controlled trial of ulinastatin for prevention of hyperenzymemia after double-balloon endoscopy via the antegrade approach. Dig Endosc 2013; 25(4) $421-427$.

70. Villa JJ, Jimenez FJ, Prieto C, et al. Utility of bolus somatostatin administration in preventing pancreatitis after endoscopic retrograde cholangiopancreatography: a controlled, non-randomized study. Gastroenterol Hepatol 2006; 29(4): 231-236.

71. Xia Q, Quan L, Yang XN, Tang WF, Jiang JM. Comparison of integrated Chinese and Western medicine with and without somatostatin supplement in the treatment of severe acute pancreatitis. World J Gastroenterol 2005; 11(7): 1073-1076.

Received: 11/05/2016 Accepted: 15/06/2016 